\title{
Effect of ramipril/hydrochlorothiazide and ramipril/ canrenone combination on atrial fibrillation recurrence in hypertensive type 2 diabetic patients with and without cardiac autonomic neuropathy
}

Daniele Bosone ${ }^{1}$, Alfredo Costa ${ }^{1,2}$, Natascia Ghiotto ${ }^{1}$, Matteo Cotta Ramusino ${ }^{1,2}$, Annalisa Zoppi ${ }^{3}$, Angela D'Angelo ${ }^{3}$, Roberto Fogari ${ }^{1}$

${ }^{1}$ Interinstitutional Center of Neurological Medicine, IRCCS C. Mondino National Neurological Institute, Pavia, Italy

${ }^{2}$ Department of Neurosciences and Behaviour, University of Pavia, Pavia, Italy

${ }^{3}$ Department of Internal Medicine and Therapeutics, University of Pavia, Pavia, Italy

Submitted: 2 February 2016

Accepted: 12 July 2016

Arch Med Sci 2017; 13, 3: 550-557

DOI: 10.5114 /aoms.2016.62448

Copyright (c) 2016 Termedia \& Banach

\section{Corresponding author:}

Prof. Roberto Fogari

Department of Neurosciences and Behaviour National Institute of Neurology IRCCS C. Mondino Foundation University of Pavia Via Mondino 2

27100 Pavia, Italy

Phone: +390382526217

E-mail: r.fogari@unipv.it

\section{Abstract}

Introduction: The aim of this study was to compare the effect of ramipril/ canrenone versus ramipril/hydrochlorothiazide (HCTZ) combination on atrial fibrillation (AF) recurrence in type 2 diabetic hypertensives with and without cardiac autonomic neuropathy (CAN).

Material and methods: A total of 289 hypertensive type 2 diabetic patients, 95 with CAN, in sinus rhythm but with at least two episodes of AF in the previous 6 months were randomized to ramipril $5 \mathrm{mg}$ plus canrenone $50 \mathrm{mg}$ (titrated to $10 / 100 \mathrm{mg}$ ) or to ramipril $5 \mathrm{mg}$ plus HCTZ $12.5 \mathrm{mg}$ (titrated to $10 / 25 \mathrm{mg}$ ) or to amlodipine $5 \mathrm{mg}$ (titrated to $10 \mathrm{mg}$ ) for 1 year. Clinic blood pressure (BP) and a 24-h ECG were evaluated monthly. Patients were asked to report any episode of symptomatic AF and to perform an ECG as early as possible. Serum procollagen type I carboxy-terminal peptide (PIP) and carboxy-terminal telopeptide of collagen type I (CITP) were evaluated before and after each treatment period. Results: Blood pressure was similarly and significantly reduced by all treatments. A total of $51 \%$ of patients with amlodipine had a recurrence of $A F$, as did $31 \%$ of patients with ramipril/HCTZ ( $p<0.05$ vs. amlodipine) and $13 \%$ of patients with ramipril/canrenone ( $p<0.01$ vs. amlodipine and $p<0.05$ vs. ramipril/HCTZ). A similar trend was found in diabetic patients with CAN. Both combinations reduced PIP and increased CITP, but the effects of rami$\mathrm{pril/canrenone} \mathrm{were} \mathrm{significantly} \mathrm{more} \mathrm{marked.}$

Conclusions: These findings suggest that in type 2 diabetic hypertensives, ramipril/canrenone treatment was more effective than ramipril/HCTZ in reducing AF recurrence. This could be related to the greater improvement in cardiac fibrosis.

Key words: diabetes mellitus, atrial fibrillation, antihypertensive treatment, canrenone, cardiac autonomic neuropathy.

\section{Introduction}

Atrial fibrillation (AF) is frequently observed in diabetic patients [1-3]. Subjects with diabetes frequently suffer from cardiac autonomic neu- 
ropathy $(\mathrm{CAN})[4,5]$, which may contribute to creation of electrical instability leading to AF [2]. The renin-angiotensin-aldosterone system (RAAS) is well known to play a major role in the pathophysiology of $A F$, being involved in myocardial fibrosis, oxidative stress, inflammation and electrical abnormalities, which all contribute to the atrial remodeling underlying the occurrence of this arrhythmia [6]. As a consequence, RAAS blockade has been shown to be effective in preventing new onset as well as recurrence of AF in a variety of clinical settings [7].

Lately the role of aldosterone in AF pathophysiology has been recognized with special focus on the effects on AF-induced structural and electrical atrial remodeling [8]. Accordingly, a positive role of aldosterone and mineralocorticoid receptor (MR) antagonism in "upstream" treatment of AF has been suggested, although no definite clinical data exist in this regard $[9,10]$. There is evidence that $M R$ antagonism may reduce the incidence of $A F$ in patients with heart failure $[10,11]$, whereas some studies suggested that it may be useful to add an aldosterone/MR antagonist to ACE-I or ARBs in patients with AF [12].

Given that treatment of hypertensive patients with diabetes almost always requires combination of two or more drugs [13], the aim of the present study was to evaluate the effect of the ACE-I ramipril plus the aldosterone antagonist canrenone as compared to ramipril/hydrochlorothiazide (HCTZ) combination in preventing the recurrence of $A F$ in hypertensive patients with diabetes mellitus and a history of a recent AF episode. The effects on P-wave dispersion (PWD), assessed as a marker of inhomogeneous atrial propagation of sinus impulses [14], were also evaluated, as were the effects on serum procollagen type 1 carboxy-terminal peptide (PIP) levels, used as a marker of extracellular collagen type 1 synthesis and myocardial fibrosis [15] and on carboxy-terminal telopeptide of collagen type 1 (CITP), used as marker of extracellular collagen type 1 degradation [12, 13]. Due to the role of CAN in AF pathophysiology, the effects of study medications were evaluated in patients with and without CAN.

\section{Material and methods}

This was a prospective, randomized, double-blind, parallel-arm trial. The study population was selected according to the following inclusion criteria: outpatients of either sex with essential hypertension (systolic blood pressure (SBP) $\geq 140$ and < $160 \mathrm{~mm} \mathrm{Hg}$ and/or diastolic blood pressure $(\mathrm{DBP}) \geq 90$ and $<100 \mathrm{~mm} \mathrm{Hg}$ at the end of a 2-week wash-out period) and well-controlled diabetes mellitus (glycated haemoglobin $\left.\left(\mathrm{HbA}_{1 \mathrm{c}}\right)<7 \%\right)$ in sinus rhythm but with at least
2 ECG-documented episodes of symptomatic AF in the previous 6 months. Previous AF episodes could be self-terminating or terminated after pharmacological and/or electrical cardioversion. Exclusion criteria were: secondary hypertension, cardioversion within the last 8 weeks, in current treatment with angiotensin converting enzyme-inhibitors (ACE-I), angiotensin II receptor blockers (ARBs) or $\beta$-blockers, antiarrhythmic agents, myocardial infarction or stroke in the previous 6 months, congestive heart failure, left atrium size > $45 \mathrm{~mm}$, need to continue the use of digitalis, cardiac surgery during the preceding 6 months, significant thyroid, renal or hepatic disease, pregnancy, and known contraindications to the study medications. The study protocol was approved by the local Ethical Committee, and informed consent was obtained from each participant.

The patients were evaluated for CAN using 4 different clinical tests: 1) heart rate variability: the standard deviation of 150 consecutive R-R intervals recorded while the subjects lay quietly breathing when $\leq 2 \mathrm{mms}$ was considered abnormal; 2) resting heart rate $(H R)$ : a resting $H R$ of more than 100 beats per minute was considered abnormal; 3) orthostatic hypotension: BP was first measured in a supine position and then after 2 min of standing; a fall in SBP of $>20 \mathrm{~mm} \mathrm{Hg}$ and/or in DBP >10 mm Hg was considered abnormal; 4) ECG recording - QTc interval > $440 \mathrm{~ms}$ was considered abnormal. If two or more of the above tests were abnormal, the patient was diagnosed as positive for CAN. We choose to use the above described tests for CAN detection instead of the widely used Ewing tests [16] because two of the latter, i.e. the Valsalva maneuver and handgrip test, require full cooperation of the patient, which would have been difficult to obtain in elderly patients such as those enrolled in the present study.

After an initial 2-week antihypertensive washout period on placebo, patients were randomly assigned to receive ramipril $5 \mathrm{mg}$ plus $50 \mathrm{mg}$ of canrenone or ramipril $5 \mathrm{mg}$ plus $12.5 \mathrm{mg}$ of HCTZ or $5 \mathrm{mg}$ of amlodipine once daily (od). In non-responder patients (BP > 135/85 mm Hg), the study drugs were titrated after 4 weeks (ramipril/canrenone $5 / 100 \mathrm{mg}$, ramipril HCTZ $5 / 25 \mathrm{mg}$ and amlodipine $7.5 \mathrm{mg}$ ) and 8 weeks (ramipril/canrenone 10/100 mg, ramipril HCTZ 10/25 mm Hg and amlodipine $10 \mathrm{mg}$ ) to achieve a target BP of less than 135/85 mm Hg (Figure 1). Those patients who did not achieve the target BP after 12 weeks were excluded. Patients were checked every 4 weeks for 1 year. Clinical examination included BP evaluation, a resting ECG and a 24-h ECG registration (using a Syneflah Holter recorder, Ela Medical, Paris, France) [17]. Patients were 
also asked to report any episode of palpitations, to take their pulse and, in presence of arrhythmia, to perform an ECG as early as possible. Only AF episodes confirmed with an ECG were considered as recurrences.

At the end of the placebo period and of each treatment period, PWD was evaluated and serum PIP and CITP levels were determined.

P-wave analysis measurements were calculated in 12-lead surface ECG recordings obtained at a paper speed of $50 \mathrm{~mm} / \mathrm{s}$ and were transferred into a computer and opened with a high-performance graphic program. Measurements of $P d u-$ ration were performed by two cardiologists blinded to the patients' clinical data. Four cycles were measured for each lead. The difference between maximum and minimum $P$ duration was defined as PWD [18]. Blood samples for PIP and CITP evaluation were taken in the morning after an overnight fast. Serum PIP was determined by a rapid equilibrium radioimmunoassay according to the method of Meikko et al. [19] using commercial antisera specifically directed against the terminal carboxy terminal peptide. Serum CITP was also determined by a specific radioimmunoassay using specific antisera (Orion Diagnostica, Espoo, Finland), according to the method of Risteli et al. [16].

The primary end-point of the study was to assess the efficacy of ramipril/canrenone combination as compared to ramipril/HCTZ combination and amlodipine with regard to the cumulative number of patients relapsing into documented atrial fibrillation. Secondary end points were time to a first ECG-confirmed recurrence of $A F$, the changes in PWD and the changes in PIP and CITP serum levels.

\section{Statistical analysis}

The sample size calculations are based on an estimated efficacy at 1 year of $75 \%$ for ramipril/ canrenone, $80 \%$ for ramipril/HCTZ and $60 \%$ for amlodipine. With a level of 0.05 and a test power of 0.80 , the resulting sample size was 87 patients for each treatment group. Data are expressed as means \pm SD for continuous variables, and frequencies were measured for categorical variables. Baseline characteristics were examined for statistical significance for continuous variables using Student's $t$-test. The Fisher exact test was used for categorical variables. The end points were analyzed on an intention-to-treat basis. The number of days to AF recurrence (median and range) was compared among the treatment groups by the non-parametric Wilcoxon test.

\section{Results}

A total of 342 consecutive hypertensive patients with type 2 diabetes were referred to our hypertension center with a history of paroxysmal AF. Of them 289 were finally randomized to participate in this study (Figure 2). Ninety-five (32.8\%) patients were found to have CAN. Forty-two patients were excluded from this protocol according to the inclusion/exclusion criteria. Twelve patients refused to participate. The baseline demographic and clinical characteristics of each treatment group are shown in Table I. Patients in the 3 groups were well matched and similar with regard to all pre-treatment characteristics.

A total of 98 patients were allocated for treatment with ramipril/canrenone combination, 97 for

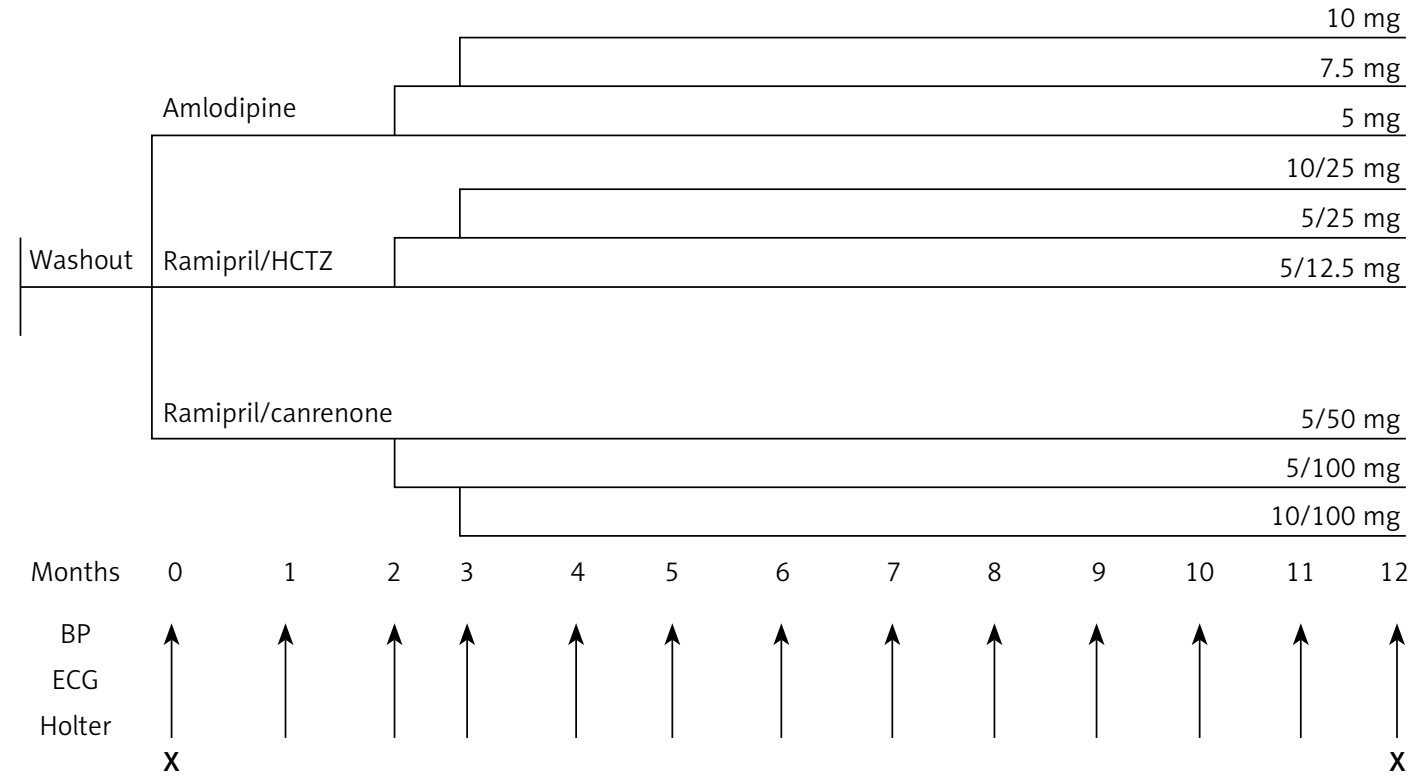

$X$ procollagen $C$ propeptide type $I$ and carboxy-terminal telopeptide

Figure 1. Study design
Patients were asked to report any episode of symptomatic AF and to perform an ECG and an evaluation of plasma cardiac troponin-I as early as possible. 


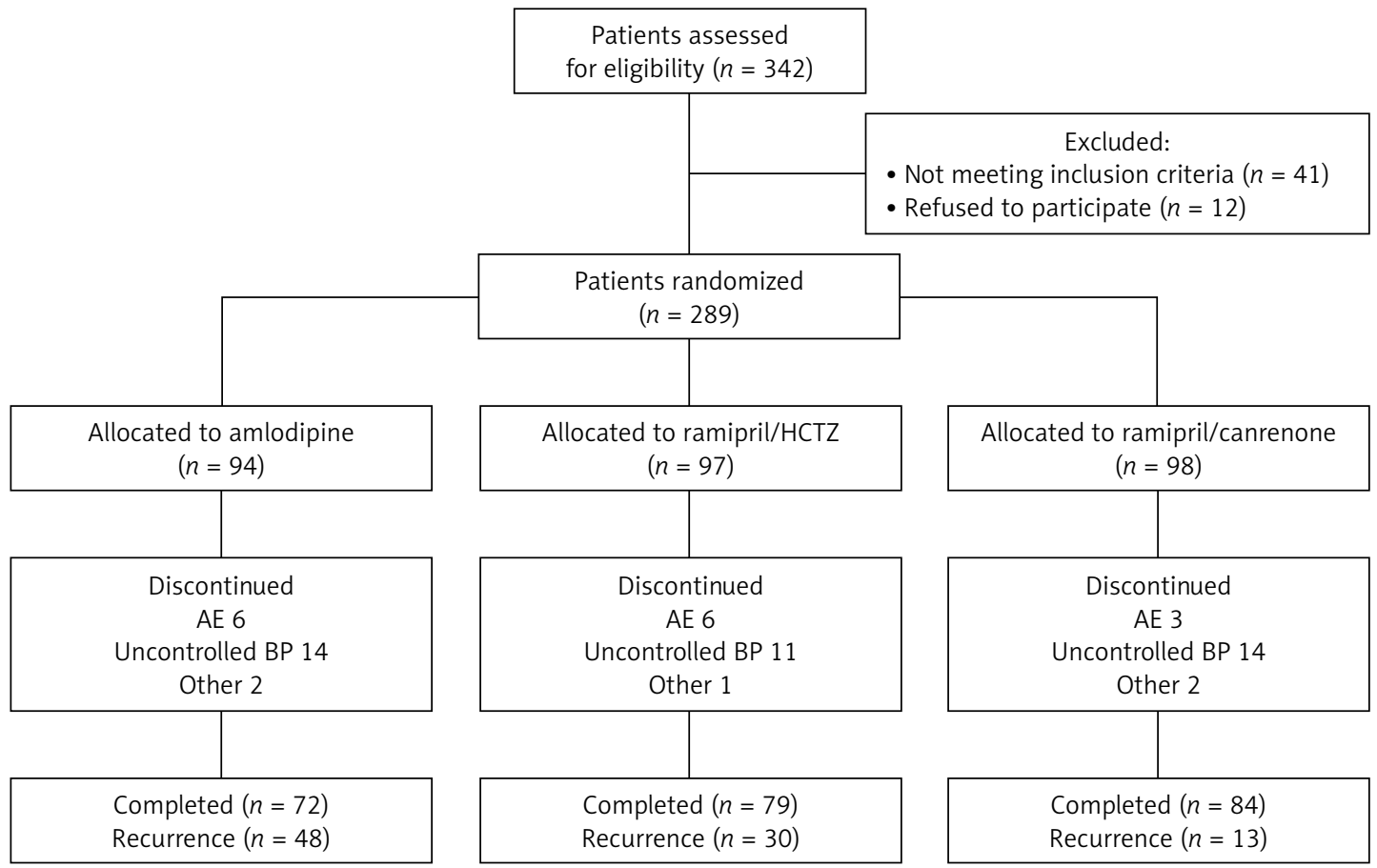

Figure 2. Flow diagram of the study

treatment with ramipril/HCTZ combination and 94 for treatment with amlodipine. There were substantial reductions in SBP and DBP values in all treatment groups. At the end of follow-up SBP was reduced by $18.9 \mathrm{~mm} \mathrm{Hg}(p<0.001)$ with rami- pril/canrenone, by $19.3 \mathrm{~mm} \mathrm{Hg}(p<0.001)$ with ramipril/HCTZ and by $17.2 \mathrm{~mm} \mathrm{Hg}(p<0.001)$ with amlodipine, with no significant difference among treatments. Corresponding changes for DBP were $14.5,14.9$ and $13.6 \mathrm{~mm} \mathrm{Hg}$ ( $p<0.001$ vs. baseline),

Table I. Main demographic and clinic characteristics of patients in the three treatment groups

\begin{tabular}{|lcccl|}
\hline Parameter & $\begin{array}{c}\text { Amlodipine } \\
(n=94)\end{array}$ & $\begin{array}{c}\text { Ramipril/HCTZ } \\
(n=97)\end{array}$ & $\begin{array}{c}\text { Ramipril/canrenone } \\
(n=98)\end{array}$ & $P$-value \\
\hline Age [years] & $68 \pm 7.5$ & $67 \pm 7.1$ & $68 \pm 8.2$ & NS \\
\hline Sex (M/F) & $45 / 49$ & $46 / 51$ & $48 / 50$ & NS \\
\hline Weight [kg] & $75.4 \pm 10.1$ & $75.7 \pm 10.5$ & $76.2 \pm 10.6$ & NS \\
\hline SBP [mm Hg] & $148.8 \pm 7.3$ & $148.2 \pm 7.5$ & $149.1 \pm 7.8$ & NS \\
\hline DBP [mm Hg] & $92.3 \pm 3.7$ & $92.7 \pm 3.5$ & $93.1 \pm 3.9$ & NS \\
\hline Heart rate [bpm] & $76.1 \pm 9.9$ & $75.9 \pm 10.8$ & $75.5 \pm 11.2$ & NS \\
\hline FPG [mg/dl] & $126.1 \pm 19.3$ & $123.4 \pm 20.2$ & $125.3 \pm 18.6$ & NS \\
\hline HbA (\%) & $6.8 \pm 0.3$ & $6.6 \pm 0.5$ & $6.7 \pm 0.4$ & NS \\
\hline Serum potassium [mEq/l] & $4.49 \pm 0.39$ & $4.43 \pm 0.36$ & $4.52 \pm 0.35$ & NS \\
\hline eGFR [ml/min/1.73 m²] & $86.6 \pm 5.9$ & $88.1 \pm 6.2$ & $83.7 \pm 5.7$ & NS \\
\hline Echocardiogram: & & & & NS \\
\hline LV end-diastolic dimension [mm] & $50.8 \pm 0.7$ & $51.5 \pm 0.6$ & $50.4 \pm 0.5$ & NS \\
\hline Ejection fraction (\%) & $61.2 \pm 8.1$ & $62.1 \pm 8.3$ & $60.7 \pm 8.9$ & NS \\
\hline LA inferosuperior dimension [mm] & $42.8 \pm 2.3$ & $42.6 \pm 2.1$ & $42.9 \pm 2.2$ & NS \\
\hline Septal thickness [mm] & $11.3 \pm 0.29$ & $11.1 \pm 0.33$ & $11.4 \pm 0.27$ & NS \\
\hline AF episodes (number) & $2.6 \pm 0.8$ & $2.8 \pm 0.9$ & $2.7 \pm 0.8$ & NS \\
\hline
\end{tabular}

Data are expressed as mean $\pm S D$. SBP - systolic blood pressure, DBP - diastolic blood pressure, FPG - fasting plasma glucose, HbA ${ }_{1 c}-$ glycated hemoglobin, eGFR - estimated glomerular filtration rate, $L V$ - left ventricular, $L A$ - left atrial, $A F$ - atrial fibrillation. 
respectively, again without any significant difference among treatments. Heart rate did not show any significant change from baseline.

Results regarding AF recurrence are shown in Tables II and III. At the 4-month follow-up visit (end of titration period), 37 patients had a recurrence of AF by intention-to-treat analysis; the occurrence rate was lower in the ramipril/canrenone group (9 patients) than in the ramipril/ HCTZ group (11 patients) and the amlodipine group (17 patients), the difference of ramipril/ canrenone vs amlodipine being statistically significant $(p<0.05)$.

At the end of the follow-up, 48 (51\%) patients undergoing treatment with amlodipine had a recurrence of $A F$, as did 30 patients (31\%) undergoing treatment with ramipril plus HCTZ ( $p<$ 0.05 vs. amlodipine) and 13 (13\%) patients undergoing treatment with ramipril plus canrenone ( $p<0.01$ vs. amlodipine and $p<0.05$ vs. ramipril/ $\mathrm{HCTZ}$ ). The time to a first ECG-confirmed recurrence of AF was of $69 \pm 31$ days (median \pm SD) in the amlodipine group, of $139 \pm 73$ days in the ramipril/HCTZ group ( $p<0.05$ vs. amlodipine) and of $175 \pm 91$ days in the ramipril/canrenone group ( $p<0.01$ vs. amlodipine and $p<0.05$ vs. ramipril/HCTZ).

Table III shows the main results according to an intention-to treat analysis in the subgroup of patients with CAN at baseline. At the end of follow-up the number of patients who had a recurrence of $\mathrm{AF}$ was lower in the ramipril/canrenone group (5) than in the ramipril/HCTZ group (12) and the amlodipine group (17). Similarly, the number of days to AF recurrence was higher in the ramipril canrenone group $(116 \pm 69)$ than in the ramipril/HCTZ group $(91 \pm 49)$ and the amlodipine group (58 \pm 25 ), but the differences among treatments were not statistically significant.

The percentage of patients with CAN who had an $\mathrm{AF}$ recurrence was not different from that of the total population in all the 3 treatment groups: $54.8 \%$ vs. $51.1 \%$ with amlodipine, $35.2 \%$ vs. $31 . \%$ with ramipril/HCTZ and 16.6 vs. $13.3 \%$ with ramipril/canrenone.

The PWD values did not show any significant change in the amlodipine treated patients, whereas a significant reduction was observed in both the ramipril/HCTZ ( $p<0.05$ vs. baseline) and the ramipril/canrenone group ( $p<0.01$ vs. baseline). Such a reduction was significantly greater in the ramipril/canrenone than in the ramipril/HCTZ treated patients $(p<0.01)$ (Table IV).

Serum PIP levels were not affected by amlodipine treatment, whereas they were reduced by both ramipril plus HCTZ ( $p<0.01$ vs. baseline and $p<0.05$ vs. amlodipine) and ramipril plus canrenone ( $p<0.01$ vs. baseline and vs. amlodipine). The reduction was significantly greater in the ramipril/canrenone than in the ramipril/HCTZ group $(p<0.01)$ (Table IV).

Serum CITP levels were not affected by amlodipine treatment, whereas they were increased by both ramipril plus HCTZ ( $p<0.05$ vs. baseline) and ramipril plus canrenone ( $p<0.01$ vs. baseline and vs amlodipine). Again the increase was significantly greater in the ramipril plus canrenone than in the ramipril/HCTZ treated patients $(p<0.05)$.

No significant change in fasting plasma glucose values was observed in the 3 treatment groups (Table V). Similarly, no significant change was ob-

Table II. Main results of the study according to an intention-to-treat analysis

\begin{tabular}{|lccc|}
\hline Variable & Amlodipine & Ramipril/HCTZ & Ramipril/canrenone \\
\hline Patients randomized & 94 & 97 & 98 \\
\hline $\begin{array}{l}\text { AF recurrence at 4 months after randomization } \\
\text { (end of titration) }\end{array}$ & 17 & 11 & $13^{\mathrm{a}}$ \\
\hline $\begin{array}{l}\text { AF recurrence at 1 year after randomization } \\
\text { (end of follow-up) }\end{array}$ & 48 & $30^{\mathrm{a}}$ & $175 \pm 91^{\mathrm{a}}(48-349)$ \\
\hline Days to recurrence, median \pm SD (range) & $69 \pm 31(28-329)$ & $139 \pm 73^{\mathrm{a}}(39-336)$ & 175 \\
\hline
\end{tabular}

${ }^{a} p<0.05$ vs. amlodipine, ${ }^{b} p<0.01$ vs. amlodipine, ${ }^{c} p<0.05$ vs. ramipril/HCTZ, AF-atrial fibrillation.

Table III. Main results according to an intention-to-treat analysis in the subgroup of patients with CAN at baseline

\begin{tabular}{|lccc|}
\hline Variable & Amlodipine & Ramipril/HCTZ & Ramipril/canrenone \\
\hline Patients & 31 & 34 & 30 \\
\hline $\begin{array}{l}\text { AF recurrence at 4 months after randomization } \\
\text { (end of titration) }\end{array}$ & 6 & 12 & 3 \\
\hline $\begin{array}{l}\text { AF recurrence at 1 year after randomization } \\
\text { (end of follow-up) }\end{array}$ & 17 & $5^{*}$ \\
\hline Days to recurrence, median \pm SD (range) & $58 \pm 25(21-211)$ & $91 \pm 49(32-229)$ & $106 \pm 69(39-244)$ \\
\hline${ }^{*} p<0.05$ vs. amlodipine. $A F-$ atrial fibrillation. & & & \\
\end{tabular}


Table IV. P-wave dispersion and serum PIP and CITP values before and after treatment in patients who completed the study without any AF recurrence

\begin{tabular}{|c|c|c|c|}
\hline Parameter & $\begin{array}{l}\text { Amlodipine } \\
\quad(n=24)\end{array}$ & $\begin{array}{c}\text { Ramipril/HCTZ } \\
(n=49)\end{array}$ & $\begin{array}{l}\text { Ramipril/canrenone } \\
\qquad(n=71)\end{array}$ \\
\hline \multicolumn{4}{|l|}{ PWD [ms]: } \\
\hline Placebo & $39.3 \pm 10.8$ & $40.2 \pm 8.7$ & $39.8 \pm 9.2$ \\
\hline Treatment & $40.1 \pm 11.9$ & $34.5 \pm 9.1^{\mathrm{a}}$ & $27.1 \pm 7.9^{\mathrm{b}, \mathrm{d}, \mathrm{e}}$ \\
\hline \multicolumn{4}{|c|}{ Serum PIP $[\mu g / I]:$} \\
\hline Placebo & $148.5 \pm 35.2$ & $147.2 \pm 34.6$ & $149.8 \pm 36.7$ \\
\hline Treatment & $138.1 \pm 32.7$ & $101.8 \pm 24.7^{\mathrm{b}, \mathrm{c}}$ & $84.2 \pm 18.3^{\mathrm{b}, \mathrm{d}, \mathrm{e}}$ \\
\hline \multicolumn{4}{|c|}{ Serum CITP $[\mu \mathrm{g} / \mathrm{l}]$ : } \\
\hline Placebo & $2.44 \pm 1.23$ & $2.48 \pm 1.26$ & $2.49 \pm 1.25$ \\
\hline Treatment & $2.49 \pm 1.28$ & $2.68 \pm 1.28^{a}$ & $3.11 \pm 1.29^{\mathrm{b}, \mathrm{d}, \mathrm{e}}$ \\
\hline
\end{tabular}

Data are expressed as mean \pm SD. ${ }^{a} p<0.05$ vs. placebo, ${ }^{b} p<0.01$ vs. placebo, ${ }^{c} p<0.05$ vs. amlodipine, ${ }^{d} p<0.01$ vs. amlodipine, ${ }^{e} p<0.05$ vs. ramipril/HCTZ. PWD - P-wave dispersion, PIP - propeptide of procollagen type I, CITP-carboxy-terminal telopeptide of collagen type I.

Table V. Adverse events and biochemical parameters at the end of the follow-up

\begin{tabular}{|c|c|c|c|c|}
\hline Parameter & $\begin{array}{l}\text { Amlodipine } \\
\quad(n=94)\end{array}$ & $\begin{array}{c}\text { Ramipril/HCTZ } \\
(n=97)\end{array}$ & $\begin{array}{l}\text { Ramipril/canrenone } \\
\qquad(n=98)\end{array}$ & $P$-value \\
\hline Adverse events & 10 & 9 & 8 & NS \\
\hline $\mathrm{FPG}[\mathrm{mg} / \mathrm{dl}]$ & $125.2 \pm 17.3$ & $126.6 \pm 19.4$ & $124.9 \pm 18.8$ & NS \\
\hline Serum potassium [mEq/l] & $4.51 \pm 0.41$ & $4.29 \pm 0.34$ & $4.67 \pm 0.39$ & NS \\
\hline $\mathrm{eGFR}\left[\mathrm{ml} / \mathrm{min} / 1.73 \mathrm{~m}^{2}\right]$ & $85.8 \pm 5.7$ & $87.4 \pm 6.3$ & $84.5 \pm 5.4$ & NS \\
\hline
\end{tabular}

Data are expressed as mean $\pm S D$. FPG - fasting plasma glucose, eGFR - estimated glomerular filtration rate.

served in serum potassium levels or glomerular filtration rate (GFR) (Table V).

Adverse events requiring the discontinuation of treatment occurred in 3 patients in the ramipril/ canrenone group, 6 patients in the ramipril/HCTZ group and in 6 patients in the amlodipine group, with no significant difference among the 3 treatment groups.

\section{Discussion}

The results of this study showed that in hypertensive patients with type 2 diabetes and a history of AF episodes antihypertensive treatment with both ramipril/canrenone and ramipril/HCTZ combination was more effective than amlodipine monotherapy in reducing new episodes of AF, but the preventive effect of ramipril plus canrenone on $A F$ relapse was significantly greater than that of ramipril plus HCTZ despite a similar BP reduction. These results were already evident after 3 months of therapy and persisted after 1 year, when the difference between the two combinations was more marked.

These findings on one hand confirm that ACE inhibition per se may be effective in preventing AF recurrence, which is in agreement with previous observations [20-22]. Such a preventive effect has been related to several mechanisms, including inhibition of angiotensin II-induced myocardial fi- brosis, interference with ion channel function, in particular $\mathrm{K}^{+}$channel subunits and $\mathrm{Ca}^{++}$ion currents, modulation of refractoriness, reduced atrial stretch, improved left ventricular hemodynamics and modulation of sympathetic nerve activity [23, 24]. On the other hand, the findings of this study indicate that adding an antialdosteronic drug such as canrenone to an ACE-I may provide a greater AF-preventing effect, possibly related to the positive impact of aldosterone inhibition on the atrial electrical and structural remodeling documented by the effects on PWD as well as on PIP and CITP levels.

Inhomogeneous atrial propagation of sinus impulses, marked by PWD, has been demonstrated to be an independent predictor for $\operatorname{AF}[14,25]$. In the present study, both combinations significantly reduced PWD, but the reducing effect of the latter was more marked. Aldosterone, whose levels are elevated in patients with AF [26], has been demonstrated to affect atrial electrophysiology via modulation of both $\mathrm{K}^{+}$and $\mathrm{Ca}^{++}$channels [27]. It increases L-type calcium currents and prolongs action potential duration, which may result in early afterdepolarizations [28]. It also alters repolarizing potassium currents [27]. Additionally, aldosterone enhances potassium and magnesium excretion, decreases myocardial reuptake of catecholamines, attenuates baroreceptor activity, increases baroreceptor sensitivity to catecholamines and re- 
duces sinus rhythm variability, mechanisms that all contribute to the arrhythmogenic potential of aldosterone. Therefore inhibition of aldosterone actions by canrenone might result in an AF-preventing effect at least in part through amelioration of atrial electrical remodeling.

Fibrosis in atrial muscles is another critical factor responsible for $A F$, mainly through decrease in the atrial conduction velocity and heterogeneity of the conduction tissue $[29,30]$. Increased interstitial fibrosis can physically separate myocytes, decreasing myocyte electrical coupling and creating a barrier to impulse propagation. Since the use of cardiac biopsies for documenting and measuring myocardial fibrosis is an invasive methodology not useful for wide-scale application, serological markers of collagen turnover have been introduced for non-invasive monitoring of myocardial fibrosis in clinical practice. In particular, serum concentrations of PIP and CITP may be useful for assessing the synthesis and degradation, respectively, of collagen type I fibers and provide indirect information on both the extent of myocardial fibrosis and the ability of antihypertensive agents to reduce myocardial fibrosis $[15,16]$. In this study, both ramipril plus HCTZ and ramipril plus canrenone significantly decreased the serum concentration of PIP and increased CITP levels, thus confirming the ability of ACE-I inhibition to reduce the synthesis and to stimulate the degradation of collagen type I fibers with consequent reduction of myocardial fibrosis [31]. These effects, however, were significantly more marked in the ramipril/ canrenone treated patients, which again indicates the relevant role of aldosterone inhibition. Several studies have shown that aldosterone promotes fibrotic atrial remodeling [32, 33]. It stimulates collagen I and III synthesis and fibroblasts by activating mineralocorticoid receptors, which promote gene transcription of fibrotic and hypertrophic proteins [8]. By blocking aldosterone at its receptor, canrenone would mitigate these effects, thereby reducing myocardial fibrosis, which in turn may result in prevention of AF recurrence.

Since an increase in aldosterone levels may occur during treatment with ACE-I due to the well-known phenomenon of aldosterone escape, caused by non-ACE-dependent Ang II forming activity mediated by chymase [34, 35], add-on therapy with an aldosterone antagonist such as canrenone may be more effective in reducing $A F$ recurrence than HCTZ addition, which is devoid of anti-aldosteronic action. As a corollary of this observation, we can hypothesize that the better AF preventive effect found in various studies with ARBs $[21,22,36,37]$ might be related to the more complete blockade of the unfavorable actions of Ang II, including aldosterone production. Indeed,
ARBs are effective on both ACE and non-ACE dependent Ang II/aldosterone formation.

Although the decrease in BP could be an important part of the mechanism of benefit observed with both ramipril/canrenone and ramipril/HCTZ combination, our study revealed no statistical difference in BP. This suggests that the greater preventive effect of ramipril plus canrenone was independent from its BP-lowering effect.

Similarly, since glycemic control was stable throughout the study period in all treatment groups, the observed difference in AF recurrence did not seem to be related to the difference in glycemic status.

In the subgroup of patients with CAN, no significant difference was observed with respect to the total population with any treatment. Reasons for these inconsistent findings are unclear, but we hypothesize that a greater sample size could perhaps have resulted in different data.

During the entire study period, the enrolled patients were given only the drugs included in the study protocol. This represents an advantage and a limitation at the same time. The advantage was the possibility of detecting exclusively the effects of the study medications. The limitation was that it was not possible to ascertain whether the observed effects would be the same or less evident in case of concomitant treatment with first-line drugs for AF such as $\beta$-blockers.

In conclusion, this study showed that antihypertensive treatment with both ramipril/canrenone and ramipril/HCTZ combination was more effective than amlodipine monotherapy in preventing AF relapse in diabetic patients with a history of AF episodes, but the effect of ramipril/canrenone was greater than that of ramipril/HCTZ. The advantage of ramipril/canrenone in preventing new episodes of AF might be related to the canrenone-mediated greater lowering effect on PWD and PIP levels and greater increasing effect on CITP levels. This in turn might reflect a more positive impact of this combination of an ACE-I with an antialdosteronic drug on atrial electrical and structural remodeling due to a more complete inhibition of the RAAS.

\section{Conflict of interest}

The authors declare no conflict of interest.

\section{References}

1. Mohaved MR, Hashenzadeh M, Jamal MM. Diabetes mellitus is strong, independent risk for atrial fibrillation and flutter in addition to other cardiovascular diseases. Int J Cardiol 2005; 105: 315-21.

2. Kanorskii SG, Kanorskaia IuS. Atrial fibrillation in patients with type 2 diabetes mellitus: specific features of development and antirecurrence therapy. Kardiologiia 2010; 50: 31-7. 
3. Bissinger A, Ruxer J, Ahmed RB, Lubinski A. Heart rate turbulence in patients with poorly controlled diabetes mellitus type 2. Arch Med Sci 2014; 10: 1073-7.

4. Arif ZA, Shaikh IA, Masood N. Cardiovascular autonomic neuropathy (CAN) in patients of type 2 diabetes mellitus: a tertiary care hospital based study. Indian Heart J 2014; 66: 751-6.

5. Kasznicki J, Drzewoski J. Heart failure in the diabetic population - pathophysiology, diagnosis and management. Arch Med Sci 2014; 10: 546-56.

6. Serra JL, Bendersky M. Atrial fibrillation and the reninangiotensin system. Ther Adv Cardiovasc Dis 2008; 2: 215-23.

7. Khatib R, Joseph P, Briel M, Yusuf S, Healey J. Blockade of the renin-angiotensin-aldosterone system (RAAS) for primary prevention of non-valvular atrial fibrillation: a systematic review and meta analysis of randomized controlled trials. Int J Cardiol 2013: 165: 17-24.

8. Mayyas F, Alzoubi KH, Van Wagoner DR. Impact of aldosterone antagonists on the substrate for atrial fibrillation: aldosterone promotes oxidative stress and atrial structural/electrical remodeling. Int J Cardiol 2013; 168: 5135-42.

9. O'Meara E, Khairy P, Chabot Blanchet M, et al. Receptor antagonists and cardiovascular mortality in patients with atrial fibrillation and left ventricular dysfunction: insights from the atrial fibrillation and congestive heart failure. Circ Heart Fail 2012; 5: 586-93.

10. Mc Cullough PA, Cowan S. Mineralcorticoid receptor an tagonists and mortality in heart failure with concurrent atrial fibrillation. Circ Heart Fail 2012; 5: 550-1.

11. Swedberg K, Zannad F, McMurray JJ, et al. Eplerenone and atrial fibrillation in mild systolic heart failure. J Am Coll Cardiol 2012; 59: 1598-603.

12. Dabrowski R, Borowiec A, Smolis-Bak E, et al. Effect of combined spironolactone-beta-blocker enalapril treatment on occurrence of symptomatic atrial fibrillation episodes in patients with a history of paroxysmal atrial fibrillation (SPIR-AF study). Am J Cardiol 2010; 106: 1609-14.

13. Aronow WS. Commentary on recent guidelines for treat ing hypertension. Arch Med Sci 2014; 10: 1069-72.

14. Dilaveris PE, Gialafos EJ. P-wave dispersion: a novel predictor of paroxysmal atrial fibrillation. Ann Noninvas Electrocardiol 2001; 6: 159-65.

15. Lopez B, Gonzales A, Varo N, Laviades C, Querejeta R, Diez J. Biochemical assessment of myocardial fibrosis in hypertensive heart disease. Hypertension 2001; 38: 1222-6.

16. Risteli J, Elomaa I, Nenni S, Vovamo A, Risteli L. Radioimmunoassay for the pyridinoline cross-linked carboxyterminal telopeptide of type 1 collagen: a new serum marker of collagen degradation. Clin Chem 1993; 39: 635-40.

17. Ewing DJ, Clarke BF. Diagnosis and management of diabetic autonomic neuropathy. Br Med J 1982; 285: 916-8.

18. Chudzik M, Cygankiewicz I, Klimczak A, Lewek J, Bartczak K, Wranicz JK. Short-term ECG recordings for heart rate assessment in patients with chronic atrial fibrillation. Arch Med Sci 2014; 10: 676-83.

19. Meikko J, Niemi S, Risteli J. Radioimmunoassay of the carboxyterminal propetide of human type I procollagen. Clin Chem 1990; 36: 1328-32.

20. Vermes E, Tardif JC, Bourassa MG, et al. Enalapril decreases the incidence of atrial fibrillation in patients with left ventricular dysfunction. Insights from the Studies Of Left Ventricular Dysfunction (SOLVD) trials. Circulation 2003; 107: 2926-31.
21. Fogari R, Derosa G, Ferrari I, et al. Effect of valsartan and ramipril on atrial fibrillation recurrence and $p$-wave dispersion in hypertensive patients with recurrent symptomatic lone atrial fibrillation. Am J Hypertens 2008; 21 : 1034-9.

22. Fogari R, Mugellini A, Zoppi A, et al. Effect of telmisartan and ramipril on atrial fibrillation recurrence and severity in hypertensive patients with metabolic syndrome and recurrent symptomatic paroxysmal and persistent atrial fibrillation. J Cardiovasc Pharmac Ther 2012; 17: 34-43.

23. Nakashima H, Kumagai K, Urata H, Gondo N, Ideishi $M$, Arakawa K. Angiotensin II antagonist prevents electrical remodeling in atrial fibrillation. Circulation 2000; 101: 2612-7.

24. Ehrlich R, Hohmloser SH, Nattel S. Role of angiotensin system and effects of its inhibition in atrial fibrillation: clinical and experimental evidence. Eur Heart J 2006; 27: $512-8$

25. Ozdemir O, Sylu M, Demir AD, et al. Does P-wave dispersion predict the atrial fibrillation occurrence after direct-current shock. Angiology 2006; 57: 93-8.

26. Goette A, Hoffmanns P, Enayati W, Meltendorf U, Geller JC, Klein HU. Effect of successful electrical cardioversion on serum aldosterone in patients with persistent atrial fibrillation. Am J Cardiol 2001; 88: 906-9.

27. Lazlo R, Bentz K, Schreieck J. Effects of aldosterone and mineralcorticoid receptor antagonism on cardiac ion channels in the view of upstream therapy of atrial fibrillation. Gen Physiol Biophys 2011; 30: 11-9.

28. Lendeckel U, Dobrev D, Goette A. Aldosterone-receptor antagonism as a potential therapeutic option for atrial fibrillation. Br J Pharmac 2010; 159: 1581-3.

29. Kallergis EM, Manios EG, Kanoupakis EM, et al. Extracellular matrix alterations in patients with paroxysmal and persistent atrial fibrillation. J Am Coll Cardiol 2008; 52: 211-5.

30. Burstein B, Nattel S. Atrial fibrosis. Mechanisms and clinical relevance in atrial fibrillation. J Am Coll Cardiol 2008; 51: 802-9.

31. Boldt A, Scholl A, Garbade J, et al. Ace-inhibitor treatment attenuates atrial structural remodeling in patients with lone chronic atrial fibrillation. Basic Res Cardiol 2006; 101: 261-7.

32. Reil JC, Hohl M, Selejan S, et al. Aldosterone promotes atrial fibrillation. Eur Heart J 2012: 33: 2098-108.

33. Lavall D, Selzer C, Schuster P, et al. The mineralcorticoid receptor promotes fibrotic remodeling in atrial fibrillation. J Biol Chem 2014; 289: 6656-68.

34. Struthers AD. Aldosterone escape during ACE inhibition therapy in chronic heart failure. Eur Heart J 1995; 16 (Suppl.): 103-6.

35. Urata H, Nishimura H, Ganten D. Chymase dependent Ang II forming system in humans. Am J Hypertens 1996; 9: 277-84.

36. Wachtell K, Letho $M$, Gerdts $E$, et al. Ang II receptor blockade reduces new-onset atrial fibrillation and subsequent stroke compared to atenolol: the Losartan Intervention for End-Point Reduction in Hypertension (LIFE) study. J Am Coll Cardiol 2005; 45: 712-9.

37. Maggioni AP, Latini R, Carson PE, et al. Valsartan reduces the incidence of atrial fibrillation in patients with heart failure: results from the Valsartan Heart Failure Trial (Val-HeFT). Am Heart J 2005; 149: 548-57. 